\title{
Effectiveness of Magnesium Sulphate with Glycerin Dressing versus Heparinoid Ointment Application on Management of Phlebitis among Patients Admitted in Selected Wards of BPKIHS
}

\author{
Amuda K. C. ${ }^{*}$, Pushpa Parajuli², Ram Sharan Mehta ${ }^{2}$, Gayananda Mandal2 \\ ${ }^{1}$ Nepalese Army Institute of Health Sciences, College of Nursing, Sanobharyang, Kathmandu, Nepal \\ ${ }^{2}$ Department of Medical-Surgical Nursing, B. P. Koirala Institute of Health Sciences, Dharan, Nepal \\ Email: *aishanikc@gmail.com
}

How to cite this paper: Amuda, K.C., Parajuli, P., Mehta, R.S. and Mandal, G. (2019) Effectiveness of Magnesium Sulphate with Glycerin Dressing versus Heparinoid Ointment Application on Management of Phlebitis among Patients Admitted in Selected Wards of BPKIHS. Modern Research in Inflammation, 8, 45-61.

https://doi.org/10.4236/mri.2019.84004

Received: October 17, 2019

Accepted: November 25, 2019

Published: November 28, 2019

Copyright $\odot 2019$ by author(s) and Scientific Research Publishing Inc. This work is licensed under the Creative Commons Attribution International License (CC BY 4.0).

http://creativecommons.org/licenses/by/4.0/

\begin{abstract}
Background: Phlebitis is the inflammation of the tunica intima of the vein. If left untreated may lead to infection or thrombus formation. Early detection and appropriate interventions reduce the occurrence and severity of cannula related phlebitis. Objective: To evaluate the effectiveness of magnesium sulphate with glycerin dressing as compared to heparinoid ointment application on management of peripheral cannula induced phlebitis. Materials and Methods: A Quasi-experimental design was carried among admitted patients in Medical-Surgical Units of BPKIHS. Out among 50 admitted patients with cannula induced phlebitis. Simple random sampling technique was used to allocate the wards to each interventional group and purposive sampling technique to select samples where instruments baseline Performa and observation scale was used to collect data. Results: The study findings revealed significantly reduction of phlebitis score after 48 hours of treatment with both interventions. Thus it was concluded that both the applications were effective in reducing level of phlebitis. Regarding effectiveness, there was a statistically significant difference in phlebitis score in both experimental groups after comparison baseline within $8,16,32,40,48$ hours of administration of intervention $(P=0.05)$. The mean visual infusion scale score was more in MSG group as compared with that of HPA group. It shows that there is more reduction of VIP score in Magnesium sulphate with glycerin (MSG) group. Conclusion: In the research, study findings revealed that Magnesium sulphate with glycerin dressing is more effective than heparinoid ointment on management of peripheral cannula induced phlebitis.
\end{abstract}




\section{Keywords}

Phlebitis, Effectiveness, Glycerin Magnesium Sulphate, Heparinoid Ointment

\section{Introduction}

Peripheral venous catheters are commonly used in hospitals to deliver intravenous therapy [1]. Peripheral venous cannulation is the insertion of a Vascular Access Device (VAD) into a peripheral vein. Phlebitis is the most common complication of intravenous therapy. The incidence of phlebitis in hospitalized patients receiving IV therapy has been reported to be as high as $80 \%$ [2]. Phlebitis is the inflammation of the tunica intima of the vein. Peripheral vascular catheter insertion sites should be monitored at a minimum of each shift using a recognized Visual Infusion Phlebitis (VIP) scale for measuring degrees or severity of phlebitis [3]. Multiple factors, related to the catheter itself or the solution infused have been associated with this common complication [4]. It is estimated that 150 million peripheral intravenous devices are placed each year in North America alone [5]. Worldwide hundreds of millions of patients are affected by health care-associated infections each year. Out of 100 hospitalized patients at any given time, 7 in developed and 10 in developing countries will acquire at least one health care-associated infection [6]. A study conducted by Singh, on 230 admitted clients in Dhulikhel Teaching Hospital Nepal resulted that in $59.1 \%$ development of phlebitis mostly very mild in nature. Incidence rate of phlebitis was associated with male sex, between 21 to 40 years of age, small Gauze catheter size, inmserted at fore arm, IV drug administration and blood product transfusion [7]. The guideline for the prevention of catheter-related infections has been developed for practitioners who insert catheters and for those who are responsible for surveillance and control of infections in the hospital, the outpatient, and home healthcare settings [8]. Glycerin is an odorless, thick, sweet-tasting, syrupy liquid with a very short molecule, having the chemical formula $\mathrm{C}_{3} \mathrm{H}_{8} \mathrm{O}_{3}$. It is composed of three carbon atoms, five hydrogen atoms, and three hydroxy or $\mathrm{OH}$ groups [9]. Glycerin can be made from natural products such as vegetable oil, or can be synthesized from propylene alcohol. The result is an alcohol-based product that is an ingredient in many skin-care products. Glycerin, also called glycerol, can be used for both cosmetic purposes and as a treatment for medical conditions of the skin. Most people are very tolerant of glycerin, without experiencing irritation. The effects of glycerin on skin are a healthier, more natural-looking appearance [10]. Heparinoid ointment is a cream/gel which is a novel form of heparin therapy for topical application [11]. Heparin also has an antiphlogistic and anti-exudative effect, thus alleviating pain and promoting tissue metabolism and the process of healing [12]. Magnesium Sulphate with Glycerin dressing and Heparinoid ointment application are found to be used widely for the management of phlebitis. It is becoming a common practice in hospitals. 
Even though glycerin magnesium sulphate and heparin ointment are widely used in hospitals, which of the intervention is more effective, is still confusing and debatable question to nurses and also there is little evidence showing about that which one is more effective and cost-effective on management of thrombophlebitis. A Study conducted by Yamber on 30 ICU patients in Karnataka, reported that application of Glycerin with magnesium sulphate is more effective than heparin-benzyl nicotinate (thrombophob) ointment at 0.05 level of significant $(t=2.301)$ on management of cannula induced thrombophlebitis [13].

Objective of the Study:

Primary Objectives:

- To evaluate the effectiveness of Magnesium sulphate with glycerin dressing versus Heparinoid ointment application on management of peripheral cannula induced phlebitis.

\section{Secondary objectives:}

- To find out the association between magnesium sulphate with glycerin dressing and heparinoid ointment application on management of phlebitis with selected socio-demographic variables.

- To find out the association between magnesium sulphate with glycerin dressing and heparinoid ointment application on management of phlebitis with selected cannula and related factors.

\section{Null Hypothesis $\left(\mathrm{H}_{\mathrm{O}}\right)$}

There is no significant difference in effectiveness of Magnesium-sulphate with glycerin dressing and heparinoid ointment application on phlebitis.

\section{Operational definitions}

- Phlebitis: It is the inflammation of the veins. In this study, phlebitis means a painful swelling and raised temperature at the intravenous infusion site along with hardness (induration), redness (erythema), and palpable vein as measured of Visual Infusion Phlebitis Scale (VIP Scale).

- Magnesium sulphate with glycerine dressing: It refers to a gauze pad soaked in warm magnesium sulphate granules saturated with glycerin, topically applied and secured with roller bandage three times a day, continuously for two days to evaluate the effectiveness of magnesium sulphate with glycerin dressing versus heparinoid ointment application on management of peripheral cannula induced phlebitis.

- Heparinoid Application: It refers to application of thrombophob ointment (containing heparin) by gentle massage, three times a day at the site of phlebitis continuously for two days which reduce inflammation, stiffness and, thus alleviate pain and promote tissue metabolism as well as the process of healing.

- Effectiveness: In this study, effectiveness refers to the degree of reduction in phlebitis by application of magnesium sulphate with glycerine dressing magsulf dressing and heparinoid ointment on two groups as measured in terms of Visual Infusion Phlebitis Scale (VIP Scale). 


\section{Materials and Methods}

\subsection{Study Design}

A Quasi-experimental design was used for the study.

\subsection{Setting and Population}

Setting: The study was conducted in medical and surgical wards of B.P. Koirala Institute of Health Sciences, Dharan, Nepal.

Population: All the patients admitted in medical and surgical wards of B. P. Koirala Institute of Health Sciences with phlebitis having peripheral intravascular cannula (PIC) in situ constitute the population of the study.

\subsection{Sampling}

Sampling Technique: Medical and Surgical units admitted patients having phlebitis was selected purposively and sample from respected wards were selected by simple random sampling technique.

\section{Sample Size:}

25 participants in Group A (application of Magnesium sulphate with glycerin). 25 participants in Group B (application of Heparinoid ointment).

\subsection{Inclusion and Exclusion Criteria}

\section{Inclusion criteria}

Patients whose phlebitis score was only in upper limbs with visual infusion phlebitis score of two or more and had not received any intervention from staffs for management were included in research.

\section{Exclusion criteria}

Patients who were not willing to participate and were under cytitoxic drugs were excluded in research.

\subsection{Research Instrument}

Questionnaire and observation were used to collect the data regarding the prevalence of phlebitis and the effective management measure for phlebitis. The tool consisted of the following items.

- Part I: It consists of socio-demographic characteristics of the participants.

- Part II: It consists of information regarding cannula and related factors.

- Part III: It consists of check-list and grading scale to assess severity of phlebitis based on Visual Infusion Phlebitis (VIP) scale.

\subsection{Data Collection Procedures}

In this study, the instruments baseline performa and observation scale were used. Baseline performa, was used to assess the subjective symptoms and observation scale to observe the objective symptoms. Visual infusion scale (VIP scale) used for measuring the phlebitis according to score. Patients have VIP score 2 or above were only as study samples. 


\section{Steps:}

- Procedure for the application of both the interventions was different.

- Pre-testing was performed before intervention.

- Magnesium sulphate with glycerin dressing was used by using soaked gauze pieces. 20 gram of magnesium sulphate was diluted in $100 \mathrm{ml}$ of glycerin and this combination was applied by using soaked gauze pieces covering with the help of roller bandage whereas heparinoid ointment was applied in a thin layer to the skin of the affected part and the surrounding area, which is absorbed by the skin within the short period of time. Thus for the subjects who receive glycerin magnesium sulphate, the medication was in constant contact with the affected area till the next application.

- Both procedure were repeated 3 times a day at interval of 8 hours continuously for 2 days.

- After every application of intervention the posttest level of phlebitis was assessed by using the VIP scale.

\subsection{Data Analysis Procedure}

Ethical Clearance: Written ethical clearance was obtained from Institutional Review Committee (IRC) of BPKIHS with IRC approval number IRC 143/074/075. Informed (verbal and written) consent was taken from each participant. Confidentiality and anonymity were maintained by writing code number instead of name of participants. All the ethics in research were followed and maintained strictly.

Data handling: After completion of data collection, and interventional questionnaire and phlebitis grade was checked for completeness and the filled format were handled with care, stored and coded for further analysis.

Coding/decoding: Serial number was given for each sample result.

Monitoring: Data was taken and sequential coding was done. Data was entered in MS Excel with the help of concerned people, guide and co-guide. After entry, data were rechecked and transfer to SPSS version 11.5 and analyzed. Finally, data will be preserved for at least five years.

Statistical methods applied: Data were entered in MICROSOFT EXCEL and were analyzed using Statistical Package for Social Sciences (SPSS) version 11.5. Descriptive statistics such as mean, standard deviation, rank were used to present socio-demographical, health-related, cannula and infusion-related variables. Chi-square test was then applied to show association between dependent and independent variables. When approximately, 95\% confidence intervals were used $\mathrm{P}<0.05$ was considered statistically significant. Wilcoxon Signed-Ranked test, Mann Whitney U test and Friedman test were used to compare between two groups.

\section{Results}

Table 1 shows surprisingly 47 years was the mean age of respondents in both 
Table 1. Socio-demographic characteristics of the participants $(n=50)$.

\begin{tabular}{|c|c|c|c|c|c|c|c|c|c|}
\hline \multirow{3}{*}{ Characteristics } & \multirow{3}{*}{ Category } & \multicolumn{4}{|c|}{ Group } & \multirow{2}{*}{\multicolumn{2}{|c|}{$\begin{array}{c}\text { Total } \\
\mathrm{n}=50\end{array}$}} & \multirow{3}{*}{$\begin{array}{c}\text { Chi } \\
\text { square } \\
\left(X^{2}\right)\end{array}$} & \multirow{3}{*}{ P-value } \\
\hline & & \multicolumn{4}{|c|}{ MSG (Group I) HPA (Group II) } & & & & \\
\hline & & $N$ & $\%$ & $\mathbf{N}$ & $\%$ & $\mathrm{n}$ & $\%$ & & \\
\hline \multirow[t]{4}{*}{ Age (in years) } & $<25$ & 6 & 24 & 7 & 28 & 13 & 26 & \multirow{4}{*}{1.586} & \multirow{4}{*}{0.663} \\
\hline & $26-45$ & 7 & 28 & 4 & 16 & 11 & 22 & & \\
\hline & $46-65$ & 6 & 24 & 9 & 36 & 15 & 30 & & \\
\hline & $>65$ & 6 & 24 & 5 & 20 & 11 & 22 & & \\
\hline Mean \pm SD & & \multicolumn{2}{|c|}{$47.56 \pm 22.66$} & \multicolumn{2}{|c|}{$47.64 \pm 20.21$} & 50 & 100 & & \\
\hline \multirow{4}{*}{ Gender } & Male & 10 & 40 & 14 & 56 & 24 & 48 & \multirow{2}{*}{1.282} & \multirow{2}{*}{0.258} \\
\hline & Female & 15 & 60 & 11 & 44 & 26 & 52 & & \\
\hline & Married & 18 & 72 & 21 & 84 & 39 & 78 & \multirow{2}{*}{1.049} & \multirow{2}{*}{0.306} \\
\hline & Separate & 7 & 28 & 4 & 16 & 11 & 22 & & \\
\hline \multirow{5}{*}{ Education } & Can't read \& write & 12 & 48 & 11 & 44 & 23 & 46 & \multirow{5}{*}{0.777} & \multirow{5}{*}{0.978} \\
\hline & Informal & 2 & 8 & 3 & 12 & 5 & 10 & & \\
\hline & Primary & 7 & 28 & 7 & 28 & 14 & 28 & & \\
\hline & Secondary & 2 & 8 & 1 & 4 & 3 & 6 & & \\
\hline & Higher & 2 & 8 & 3 & 12 & 5 & 10 & & \\
\hline
\end{tabular}

groups. Almost equal number of participants were from both gender $24(48 \%)$ and $26(52 \%)$ from male and female gender respectively. Maximum 39 (78\%) were married and majority can't read and write. There was homogenous distribution of age, gender, marital status and education in both experimental groups with significance p-value of $0.663,0.258,0.3006$ and 0.978 respectively as there was no significant difference of demographic characteristics among both experimental groups (considering a P-value of 0.05).

Table 2 depicts majority of $40(80 \%)$ participants days of hospital stay was below 1 week among both MSG and HPA group, majority about two fifth 10 (40\%) of cannula was inserted in wrist in HPA group and equal number of the participants $(16 \%)$ of cannula was on forearm from both groups and equal (28\%) in both dorsum of hand and cubital fossa in MSG group. Most 38 (76\%) of the participants were cannulated with less than and equal to $20 \mathrm{G}$ cannula Frequency of cannula insertion was more than and equal to second time of nearly $90 \%$ among both groups. Types of illness, days of hospital stay, cannula insertion site, size of cannula and frequency of insertion shows no statistical significance so both groups are homogenously significant with P-value of (0.05).

Table 3 shows variables related to administration of intravenous cannula from both groups all 50 (100\%) participants received intravenous drugs. similarly 24 (96\%) participants were receiving intravenous fluids and electrolytes Likewise 15 (60\%) and 5 (20\%) participants in MSG and HPA groups respectively 
Table 2. Cannula related factors of the participants $(n=50)$.

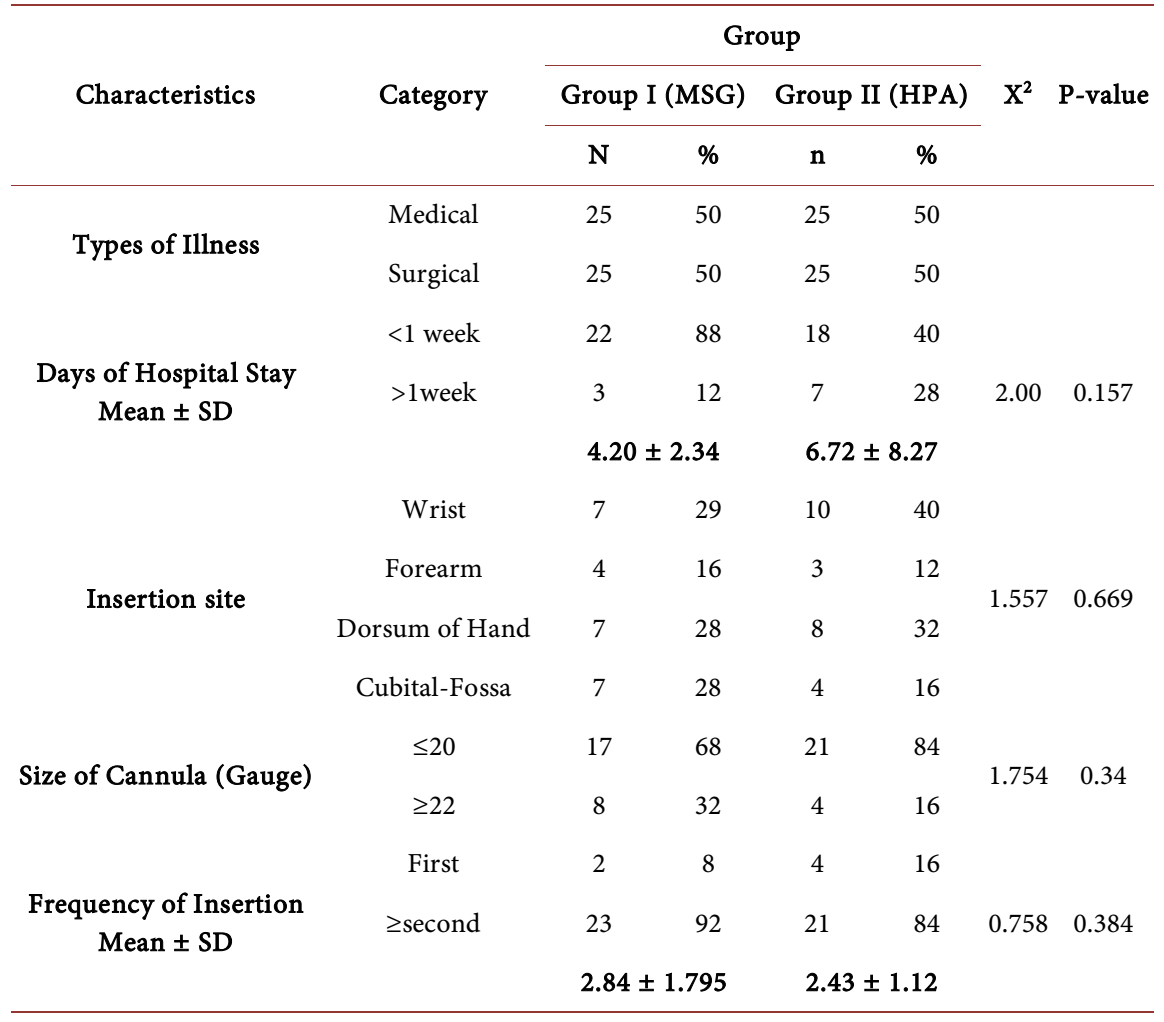

Table 3. Purpose of intravenous cannula in the participants $(n=50)$.

\begin{tabular}{|c|c|c|c|c|c|c|c|c|c|c|}
\hline \multirow{3}{*}{$\begin{array}{l}\text { Purpose of } \\
\text { IV cannula** }\end{array}$} & \multicolumn{8}{|c|}{ Groups } & \multirow{3}{*}{$\begin{array}{l}\text { Test } \\
\text { score }\end{array}$} & \multirow{3}{*}{ P-value } \\
\hline & \multicolumn{4}{|c|}{ MSG (Group I) } & \multicolumn{4}{|c|}{ HPA (Group II) } & & \\
\hline & Yes (n) & $\%$ & No $(\mathrm{n})$ & $\%$ & Yes $(n)$ & $\%$ & No $(n)$ & $\%$ & & \\
\hline Blood transfusion & 8 & 32 & 17 & 68 & 1 & 4 & 24 & 96 & 6.640 & $0.23^{\star}$ \\
\hline Drug administration & 25 & 100 & 0 & 0 & 25 & 100 & 0 & 0 & \multicolumn{2}{|c|}{ NA } \\
\hline Unconscious or nil/oral & 6 & 24 & 19 & 76 & 3 & 12 & 22 & 88 & 1.220 & $0.463^{*}$ \\
\hline Fluid electrolytes & 24 & 96 & 1 & 4 & 24 & 96 & 1 & 4 & \multicolumn{2}{|c|}{ NA } \\
\hline KCL with IVF & 15 & 60 & 10 & 40 & 5 & 20 & 20 & 80 & 8.333 & $0.009^{*}$ \\
\hline
\end{tabular}

** Multiple Response, Fisher's Exact Test*.

were under KCL with IVF similarly few were under Blood transfusion and in $\mathrm{NPO} /$ unconscious.

Table 4 depicts that majority of $16 \%$ and $80 \%$ participants had pain along the pathway in MSG and HPA groups. Similarly, medium stage or moderate phlebitis was observed in 28 (56\%) of the participants as scored by "3" among both groups out of them $44 \%$ and $68 \%$ in MSG and HPA groups respectively. 14 (28\%), 7 (14\%) 1 (2\%) of them had advanced or severe, early/mild and advanced thrombophlebitis or very severe phlebitis respectively.

Table 5 depicts reduction in mean, standard deviation and rank score from pre-score to post-score. So, the difference between pre and post-score was found 
Table 4. Severity of phlebitis based on VIP score of the participants $(n=50)$.

\begin{tabular}{|c|c|c|c|c|c|c|}
\hline \multirow{3}{*}{$\begin{array}{c}\text { Observation } \\
\text { Sign \& Symptoms of Phlebitis }\end{array}$} & \multicolumn{4}{|c|}{ Groups } & \multirow{3}{*}{$\begin{array}{c}\text { Chi } \\
\text { square } \\
\left(x^{2}\right)\end{array}$} & \multirow{3}{*}{ P-value } \\
\hline & \multicolumn{4}{|c|}{ Group I (MSG) Group II (HPA) } & & \\
\hline & $\mathrm{N}$ & $\%$ & $\mathrm{~N}$ & $\%$ & & \\
\hline \multicolumn{7}{|l|}{ Presence of pain } \\
\hline - Cannula insertion site & 11 & 44 & 5 & 20 & 3.309 & 0.069 \\
\hline - Along the path way & 16 & 64 & 20 & 80 & 1.587 & 0.208 \\
\hline Presence of Erythema & 23 & 92 & 20 & 80 & 1.495 & 0.221 \\
\hline Presence of Swelling & 18 & 72 & 22 & 88 & 2 & 0.157 \\
\hline Presence of Induration & 9 & 36 & 5 & 20 & 1.587 & 0.208 \\
\hline Presence of Palpable Venous Cord & 6 & 24 & 2 & 8 & 2.381 & 0.123 \\
\hline Pyrexia & 2 & 8 & 1 & 2 & 4.90 & 0.086 \\
\hline \multicolumn{7}{|l|}{ Severity of Phlebitis based on obtained } \\
\hline \multicolumn{7}{|l|}{ VIP Score } \\
\hline 0 (No Phlebitis) & 0 & 0 & 0 & 0 & & \\
\hline 1 (Possible first sign/very mild) & 0 & 0 & 0 & 0 & & \\
\hline 2 (Early stage/Mild) & 3 & 12 & 4 & 16 & & \\
\hline 3 (Medium stage/Moderate) & 11 & 44 & 17 & 68 & 5 & 0.172 \\
\hline 4 (Advanced phlebitis/severe) & 10 & 40 & 4 & 16 & & \\
\hline 5 (Advanced Thrombophlebitis/Very severe) & 1 & 4 & 0 & 0 & & \\
\hline
\end{tabular}

Table 5. Effectiveness of magnesium sulphate with glycerin dressing (MSG) and heparinoid ointment application (HPA) on management of phlebitis.

\begin{tabular}{ccccccc}
\hline \multirow{2}{*}{ Variables } & \multicolumn{2}{c}{ Pre-score } & \multicolumn{2}{c}{ Post-score } & WST & P-value \\
\cline { 2 - 6 } & Mean \pm SD & Rank & Mean \pm SD & Rank & & \\
\hline $\begin{array}{c}\text { Group I (MSG) } \\
(\mathrm{n}=25)\end{array}$ & $3.36 \pm 0.757$ & 6.80 & $0.120 \pm 0.332$ & 1.98 & -4.453 & $<0.001^{*}$ \\
$\begin{array}{c}\text { Group II (HPA) } \\
(\mathrm{n}=25)\end{array}$ & $3.00 \pm 0.577$ & 6.54 & $0.28 \pm 0.458$ & 1.58 & -4.500 & $<0.001^{*}$ \\
\hline
\end{tabular}

$\mathrm{P}(<0.05)^{\star}$, WST (Wilcoxon Sign Test).

to be significant. The average score has been reduced on post-test score in both groups.

Table 6 demonstrates that there is a statistically significant difference in VIP score among the participants in magnesium sulphate with glycerin group and heparinoid ointment groups after each intervention $(\mathrm{P}<0.05)$.

Table 7 Demonstrate that there is a statistically significant difference in phlebitis score in both experimental groups MSG and HPA groups after comparison baseline within $8,16,32,40,48$ hours of administration of intervention $(\mathrm{P}=$ 0.05). The mean VIP score is more in MSG group as compared with that of HPA group. It shows that there is more reduction of VIP score in MSG group.

Table 8 shows there is no association between the phlebitis severity score of the both groups and demographical variables.

Table 9 shows there is no association between the phlebitis severity score of both groups and treatment-related variables. 
Table 6. Comparision of the effectiveness of magnesium sulphate with glycerine and heparinoid ointment application on phlebitis $(n=50)$.

\begin{tabular}{|c|c|c|c|c|c|c|c|c|}
\hline \multirow{3}{*}{ Difference } & \multicolumn{8}{|c|}{ GROUP } \\
\hline & \multicolumn{4}{|c|}{ MSG (Group I) $n=25$} & \multicolumn{4}{|c|}{ HPA (Group II) $n=25$} \\
\hline & Mean \pm SD & $\begin{array}{c}\text { Mean } \\
\text { Rank }\end{array}$ & $\mathrm{X}^{2}$ & P-value & Mean \pm SD & $\begin{array}{c}\text { Mean } \\
\text { Rank }\end{array}$ & $\mathrm{X}^{2}$ & P-value \\
\hline Baseline Score & $3.36 \pm 0.757$ & 6.80 & & & $3 \pm 0.577$ & 6.54 & & \\
\hline After 8 hrs & $2.48 \pm 0.918$ & 5.94 & & & $2.56 \pm 0.768$ & 6.02 & & \\
\hline After 16 hrs & $1.80 \pm 0.816$ & 4.90 & & & $1.96 \pm 0.61$ & 4.92 & & \\
\hline After $24 \mathrm{hrs}$ & $1.04 \pm 0.841$ & 3.64 & 135.544 & $<0.01^{\star}$ & $1.48 \pm 0.65 /$ & 3.92 & 133.372 & $<0.01^{*}$ \\
\hline After 32 hrs & $0.48 \pm 0.653$ & 2.58 & & & $0.92 \pm 0.653$ & 2.86 & & \\
\hline After $40 \mathrm{hrs}$ & $0.24 \pm 0.436$ & 2.16 & & & $0.6 \pm 0.577$ & 2.16 & & \\
\hline After $48 \mathrm{hrs}$ & $0.12 \pm 0.332$ & 1.98 & & & $0.28 \pm 0.458$ & 1.58 & & \\
\hline
\end{tabular}

Friedman test, $(\mathrm{P}<0.05)^{*}$.

Table 7. Comparison of the effectiveness of magnesium sulphate with glycerine and heparinoid ointment application on phlebitis with comparison with baseline score.

\begin{tabular}{ccccccc}
\hline \multirow{2}{*}{ Difference } & \multicolumn{2}{c}{ MSG (Group I) $\mathbf{n}=\mathbf{2 5}$} & \multicolumn{2}{c}{ HPA (Group II) $\mathbf{n}=25$} & MWU & P-value \\
\cline { 2 - 6 } & Mean \pm SD & Mean Rank & Mean \pm SD & Mean Rank & & \\
\hline Baseline vs 8 hrs & $0.88 \pm 0.781$ & 28.48 & $0.44 \pm 0.660$ & 21.56 & 214 & $0.036^{\star}$ \\
Baseline vs 16 hrs & $1.56 \pm 0.711$ & 29.24 & $1.04 \pm 0.734$ & 20.76 & 194 & $0.012^{\star}$ \\
Baseline vs 24 hrs & $2.32 \pm 0.748$ & 30.76 & $1.52 \pm 0.714$ & 18.88 & 147 & $0.001^{*}$ \\
Baseline vs 32 hrs & $2.88 \pm 0.665$ & 30.80 & $2.08 \pm 0.702$ & 18.60 & 140 & $<0.001^{\star}$ \\
Baseline vs 40 hrs & $3.12 \pm 0.725$ & 30.34 & $2.4 \pm 0.577$ & 19.14 & 53 & $0.001^{\star}$ \\
Baseline vs 48 hrs & $3.24 \pm 0.723$ & 28.94 & $2.72 \pm 0.678$ & 19.65 & 196.5 & $0.014^{\star}$ \\
\hline
\end{tabular}

MWU-Mann Whitney U Test.

Table 8. Association between socio-demographic variables and severity score $(n=50)$.

\begin{tabular}{|c|c|c|c|c|c|c|c|}
\hline \multirow[b]{2}{*}{ Characteristics } & \multirow[b]{2}{*}{ Category } & \multicolumn{3}{|c|}{ Group I (MSG) } & \multicolumn{3}{|c|}{ Group II (HPA) } \\
\hline & & $\mathbf{n}$ & Mean Rank & $\begin{array}{l}\text { Test score } \\
\text { (P-value) }\end{array}$ & $\mathrm{n}$ & $\begin{array}{l}\text { Mean } \\
\text { Rank }\end{array}$ & $\begin{array}{c}\text { T score } \\
\text { (P-value) }\end{array}$ \\
\hline \multirow{4}{*}{ Age } & $<25$ & 6 & 7.33 & & 7 & 9.50 & \multirow{4}{*}{$\begin{array}{c}3.657 \\
(0.301)^{\mathrm{b}}\end{array}$} \\
\hline & $26-45$ & 7 & 14.07 & 7.482 & 4 & 13.75 & \\
\hline & $45-65$ & 6 & 18.5 & $(0.058)^{b}$ & 9 & 12.83 & \\
\hline & $>65$ & 6 & 11.92 & & 5 & 17.60 & \\
\hline \multirow{2}{*}{ Gender } & Male & 10 & 15.15 & 53.50 & 14 & 13.57 & \multirow{2}{*}{$\begin{array}{c}69 \\
(0.687)^{\mathrm{a}}\end{array}$} \\
\hline & Female & 15 & 11.57 & $(0.238)^{\mathrm{a}}$ & 11 & 12.27 & \\
\hline \multirow{2}{*}{ Marital status } & Married & 18 & 14.28 & 40 & 21 & 12.61 & \multirow{2}{*}{$\begin{array}{c}34 \\
(0.592)^{\mathrm{a}}\end{array}$} \\
\hline & Single & 7 & 9.71 & $\left(0.178^{\mathrm{a}}\right.$ & 4 & 15 & \\
\hline \multirow{5}{*}{ Educational Status } & Can't read \& write & 12 & 11.5 & & 11 & 14.73 & \multirow{5}{*}{$\begin{array}{c}4.490 \\
(0.344)^{\mathrm{b}}\end{array}$} \\
\hline & Informal & 2 & 17.75 & & 3 & 15.33 & \\
\hline & Basic & 7 & 15.21 & $\begin{array}{c}5.553 \\
(0.237)^{\mathrm{b}}\end{array}$ & 7 & 8.07 & \\
\hline & Secondary & 2 & 4.75 & & 1 & 16 & \\
\hline & Higher & 2 & 17.75 & & 3 & 14.83 & \\
\hline
\end{tabular}

$\mathrm{a}=$ Mann-Whitney U Test $\mathrm{b}=$ Kruskal Wallis Test. 
Table 9. Association between cannula related factors and severity of phlebitis $(n=50)$.

\begin{tabular}{cccccccc}
\hline & & \multicolumn{3}{c}{ Group I (MSG) } & \multicolumn{3}{c}{ Group II (HPA) } \\
\cline { 3 - 8 } Characteristics & Category & $\mathbf{n}$ & $\begin{array}{c}\text { Mean } \\
\text { Rank }\end{array}$ & $\begin{array}{c}\text { Test score } \\
\text { (P-value) }\end{array}$ & N & $\begin{array}{c}\text { Mean } \\
\text { Rank }\end{array}$ & $\begin{array}{c}\text { T score } \\
\text { (P-value) }\end{array}$ \\
\hline $\begin{array}{c}\text { Days of Hospital } \\
\text { stay }\end{array}$ & $<1$ week & 22 & 13.09 & 31 & 18 & 12 & 45 \\
& $>1$ week & 3 & 12.33 & $(0.906)^{\mathrm{a}}$ & 7 & 15.57 & $(0.297)^{\mathrm{a}}$ \\
& Wrist & 7 & 11.64 & & 10 & 11.25 & \\
$\begin{array}{c}\text { Insertion site } \\
\text { Forearm }\end{array}$ & 4 & 15 & 0.888 & 3 & 15 & 5.912 \\
& Dorsum of Hand & 7 & 12 & $(0.828)^{\mathrm{b}}$ & 8 & 17.25 & $(0.116)^{\mathrm{b}}$ \\
$\begin{array}{c}\text { Size of cannula } \\
\text { (Gauge) }\end{array}$ & Cubital fossa & 7 & 14.21 & & 4 & 7.38 & \\
$\begin{array}{c}\text { Frequency } \\
\text { of Insertion }\end{array}$ & $>20 \mathrm{G}$ & 17 & 13.21 & 64.50 & 21 & 13.43 & 33 \\
\hline
\end{tabular}

$\mathrm{a}=$ Mann-Whitney U Test, $\mathrm{b}=$ Kruskal Wallis test.

\section{Discussion}

This topic discusses on the main findings of the present study and these are discussed with regards to findings of other relevant studies. The discussions are depicted on broad headings of:

\section{Socio-demographic Characteristics of the Respondents}

According to age in years maximum numbers of the participants $30 \%$ were from the age group of 46 - 65 years in both MSG as well as HPA group. Surprisingly 47 years was the mean age of respondents in both groups. This finding is supported by study conducted in India where they found that incidence of phlebitis is lower in patients older than 60 years than below 60 years Cicolini [14] also reported equal numbers of participants $24 \%$ were from below 25 years, 46 65 and $>65$ years of age group in MSG group. The finding is consistent with that of study conducted in Intensive care unit (ICU) of Susa city Hospital conducted on 224 patients. They identified that the higher frequency for complication was found in the age group of 30 to 60 years old [15]. The reason of lower rate of phlebitis among age above 65 years may be due to impaired inflammatory response in the elderly that result in subtle sign and symptoms of phlebitis.

A small gender difference was observed in the participants in the present study with the findings of $48 \%$ in male and $52 \%$ in females from both groups. So from study finding, it is supposed that gender has no significant role in phlebitis. Some research findings have showed male gender has more phlebitis than female sex [7] [14] where as in some studies majority of subjects were female $60 \%$ in MSG and male 56\% and HPA group the finding is consistent with that of the previous finding from the study by Tan, where results showed that female patients had a significant increased risk of developing thrombophlebitis. The reasons for such differences are hard to explain and have no satisfactory explana- 
tion for such findings [16]

Similarly, majority of participants $72 \%$ and $84 \%$ in MSG group and HPA group respectively were married. Maximum $78 \%$ of participants were married from both MSG and HPA group. Majority of $148 \%$ and $44 \%$ in MSG group and HPA group respectively can't read and write. However, our data did not provide sufficient statistical evidence to prove and validate the result.

There was homogenous distribution of age, gender, marital status and education in both experimental groups with significance p-value of $0.663,0.258$, 0.3006 and 0.978 respectively.

An equal number of participants were taken having medical and surgical problems. Majority of $80 \%$ participants days of hospital stay was below 1 week among both MSG and HPA groups out of them $40 \%$ and $88 \%$ were in MSG group and HPA group respectively the study is inconsistent with the study by Abdul it shows that phlebitis per patient was associated with longer hospital stay [17].

Regarding insertion site, the present study found that the most common location for insertion of cannula was in wrist 34\% followed by Dorsum of hand 30\% among both groups among them the least $14 \%$ was forearm; $22 \%$ was reported in the cubital fossa. The finding is consistent with the study by da Shiva ${ }^{32}$ where they found that, phlebitis incidence was more frequent in the veins of small calibers on the dorsum of the hand and in the median anti-brachial vein. Similarly, this study confirms the findings of some other studies as well Wait [18] that site of insertion of cannula influence phlebitis.

However the study finding is contradictory to the findings from other studies Singh [7] reported that phlebitis was higher if inserted in forearm $65.5 \%$, followed by dorsum of hand $54.7 \%$ and wrist joint $53.3 \%$. Whereas the finding is inconsistent with the findings from other studies Hedayatinejad, Yoong [15] [19] which showed that insertion site did not significantly influence so no significant correlation seen between the insertion site and phlebitis.

This study found that cannula of $16 \mathrm{G}, 18 \mathrm{G}$ and $20 \mathrm{G}$ predicts more than $22 \mathrm{G}$ cannula among both groups the most common catheter used was size $\leq 20 \mathrm{G}$ which was approximately eighty percentage i.e. 38 (76\%) out of them majority of $21(84 \%)$ and 17 (68\%) of the respondents were cannulated with $\leq 20 \mathrm{G}$ cannula in HPA and MSG group respectively. A study conducted by Wallis, Singh [18] [20] established larger catheter size $\leq 20 \mathrm{G}$ (18 or smaller gauze) predicts phlebitis. Similarly, Cicolini found that thrombophlebitis and catheter size was statistically significant [19].

Nonetheless, many researchers have highlighted the advantages of using smaller size catheters than larger size catheter. Small size catheters allow more blood flow in adjacent tissues and thereby prevent damage to the tunica intima of the vein.

Approximately $90 \%$ participants among both groups cannula were inserted frequently which was more than twice among them majority of $92 \%$ and $84 \%$ in MSG and HPA groups respectively. However this result did not exactly provide 
sufficient statistical evidence to prove and validate this result but Marino [21] showed that the incidence of phlebitis increases significantly after peripheral vein catheters are left in place longer than 72 hours, but the incidence does not change from 72 to 96 hours. Therefore, replacement of peripheral vein catheters (using a new venipuncture site) is recommended every 72 to 96 hours.

Types of illness, days of hospital stay, cannula insertion site, size of cannula and frequency of insertion shows no statistical significance so both groups are homogenously significant with P-value of (0.05).

\section{Association of Socio-Demographic Variables and Severity Score}

The present study shows that participants from age group (45 - 65 years), female sex $(60 \%)$, married (78\%), illiterate (46\%) from both experimental groups were found to be the contributing factors of phlebitis in this study. But the association was not statistically significant.

The present study shows there is no association between socio-demographic variables which included age, gender, marital education and educational level with severity score which include after complete interventions scores $(8,16,24$, $32,40,48$ hours) of participants in both experimental groups. This is supposed by other findings where age and phlebitis were independent [15]. However, there are no more studies to support this finding.

Similarly, participants days of hospital stay less than one week, insertion site (wrist 34\%), less than $20 \mathrm{G}$ size of cannula, more than second time insertion of cannula, administration of various drugs, fluid and electrolytes, KCL were found to be contributing factors of phlebitis from both experimental groups. But the association was not statistically significant. The present study shows there is no association between treatment-related variables which included with severity score which include complete interventions scores $(8,16,24,32,40,48$ hours) of participants in both experimental groups. However there are no more studies to support this finding.

\section{Purpose of Intravenous Cannula}

The findings from the current study show that both group all $100 \%$ participants having phlebitis were using cannula for various intravenous medications followed by $96 \%$ participants were receiving intravenous fluids and electrolytes Likewise $60 \%$ and 20\% participants in MSG and HPA groups respectively were under KCL with IVF. Similarly few were under blood transfusion and in $\mathrm{NPO} /$ unconscious. This finding is supported by a study Bare [2] who explained peripheral intravenous device (PIV)/catheters are the most commonly used intravenous device in hospitalized patients. They are primarily used for therapeutic purposes such as administration of medications, fluids and/or blood products as well as blood sampling. This finding is supported by a study done in Kathmandu by singh [7] where they found that the administration of IV antibiotics substantially increase the risk of phlebitis. Multivariate analysis for risk factors for phlebitis done by Oliveira [22] showed that KCL infusion and IV antibiotics to be important risk factor which is supported by a study Saini [23]. 
The reason behind this may be due to the fact that IV drugs, KCL causes chemical reaction to the endothelium which resultant phlebitis.

\section{Severity of Phlebitis}

The present study shows that majority of $16 \%$ and $80 \%$ participants had pain along the pathway in MSG and HPA groups respectively, followed by $44 \%$ and $20 \%$ pain in cannula insertion site in MSG and HPA groups respectively. More than $80 \%$ participants had erythema in both MSG and HPA groups. Swelling was observed in $72 \%$ and $88 \%$ in MSG and HPA groups respectively. Only in some participants palpable venous cord and pyrexia was present in both groups. However, our data did not provide sufficient statistical evidence to prove and validate this result.

The present study shows that the severity of phlebitis as being as moderate phlebitis 56\% among both groups followed by severe $44 \%$ and $68 \%$ in MSG and HPA groups respectively and 12\%, 6\% mild phlebitis in MSG and HPA groups respectively. The grading of severity of phlebitis was done based on scores obtained by using VIP scale. This finding is supported by a study by Tan [16] where found that similarly $65 \%$ mild, $19 \%$ moderate and $8 \%$ severe thrombophlebitis in the study participants.

However this finding is contradictory to the finding of other studies. A study conducted in India by Saini [23] found grade 2 or mild phlebitis (46\%) higher than grade 3 or moderated (44\%) phlebitis. A study conducted by Cicoloni ${ }^{33}$ also found first degree thrombophlebitis to be the highest (84.4\%). similarly mild $53.6 \%$ and very mild $37 \%$ where found on study conducted by Oliveira and Parreira [22] [24]. Similarly, a study conducted in KU Nepal by Singh [7] found very mild (40\%) and mild (11.3\%) grades were seen to the higher than moderate (3.9\%) and severe (3.9\%) phlebitis.

Effectiveness of Magnesium Sulphate with Glycerin and Heparinoid Ointment Application on Phlebitis

The result revealed that in group I the mean pre-post treatment score of phlebitis were 3.36 and 0.120 respectively and the pre-test and post-test scores of standard deviation were 0.757 and 0.332 respectively and rank 6.80 and 1.98 respectively. In group II the mean pre-treatment and post-treatment scores of phlebitis were 3.0 and 0.28 respectively and the pre-test and post-test scores of standard deviation were 0.577 and 0.458 and rank 6.54 and 1.58 respectively which presents the mean score of different groups with pre score and post score. The difference between pre and post-treatment score was found to be significant. The average score has been reduced on post $r$ score in both groups score. Thus it was concluded that both the applications were effective in reducing level of phlebitis. This finding of the study is being supported by the study conducted Yamber [13] on 30 ICU patients in Karnataka, which showed the difference between pre and post score was found to be significant. The average score was reduced on post-treatment score in both groups. Thus it was concluded that both the applications were effective in reducing level of phlebitis. 


\section{Comparison of the Effectiveness of Magnesium Sulphate with Glycerine and Heparinoid Ointment Application on Phlebitis}

The present study demonstrates that there is a statistically significant difference in VIP score among the participants in magnesium sulphate with glycerin group and heparinoid ointment groups after each intervention $(\mathrm{P}<0.05)$.

Further the study demonstrates that there is a statistically significant difference in phlebitis score (VIP score) in both experimental groups MSG and HPA groups after comparison baseline within 8,16,32,40, 48 hours of administration of intervention ( $\mathrm{P}=0.05)$. The mean VIP score is more in MSG group as compared with that of HPA group. It shows that there is more reduction of VIP score in Magnesium Sulphate with Glycerin (MSG) group. So it is revealed that Magnesium Suphate with Glycerin is more effective than Heparinoid ointment in management of phlebitis. The finding of the study is consistent with others studies. A Study conducted by Yamber [13] on 30 ICU patients in Karnataka, reported that application of Glycerin with Magnesium Sulphate is more effective than heparin-benzyl nicotinate (thrombophob) ointment at 0.05 level of significant $(t=2.301)$ on management of cannula induced thrombophlebitis. Similarly, a study on Hospital of Vadodara to evaluate the effectiveness of Magnesium Sulphate with Glycerin dressing on Phlebitis among patients undergoing Peripheral Intravenous Infusion by Ravindra [25] revealed that magnesium sulphate with glycerin dressing was highly effective to decrease phlebitis level to the patients. Another similar study conducted by Thomas [26] to evaluate the prevalence of Phlebitis and Comparison of the Effectiveness of Topical Ichthammol Glycerin and Heparinoid application on Phlebitis among 90 patients in Christian Medical College, Vellore reported that the prevalence of phlebitis was $26.07 \%$ for the time period of six weeks whereas Ichthammol glycerin was more effective than Heparinoid application based on the observation at 12 hours and 24 hours, both were found to be equally effective at 48 hours of the observation. But finally after comparison, Ichthammol glycerin was found as more effective for the management of phlebitis.

Likewise a study found out the most effective applicant for reduction of phlebitis in comparison of Heparinoid and Ichthammol glycerine. in Christian Medical College and Hospital, Ludhiana, Punjab among 60 subjects (30 with Heparinoid and 30 with Ichthammol Glycerine applications with matching age, gender and type of disease condition) reported that both the applications were effective in reducing IV induced phlebitis [11].

Another similar study to find effectiveness of Magnesium sulphate crystal fomentation versus paste application for phlebitis in Regional Advanced Care Center, Mangalore reported that Glycerin magnesium sulphate paste was more effective compared to magnesium sulphate crystal fomentation in reducing swelling and induration [27].

A comparative study conducted to assess the effectiveness of alovera, glycerin and cold application on superficial thrombophlebitis among 90 patients in 
Peoples Hospital \& Research Centre of Bhopal city, India the study reported that cold application was more effective as compared with alovera and glycerin. In association with demographic variables there was a significant difference found between these alovera, glycerin and cold application. Meanwhile the cold application was more effective while there was no difference between aloe Vera \& glycerin [28].

Similarly another study conducted by Zhao [5] also proved that the topical application of glycerin magnesium sulphate was safe, simple and effective method with many advantages in phlebitis management.

There is a significant difference in effectiveness of magnesium sulphate with glycerin dressing and heparinoid ointment application on phlebitis so the null hypothesis has been rejected at the interval of $(\mathrm{P}>0.05)$.

\section{Conclusions}

Based on the findings of the study, both magnesium sulphate with glycerin dressing and heparinoid ointment application were effective in management of peripheral cannula induced phlebitis $(\mathrm{p}<0.001)$ but among them the mean VIP score is more in MSG group as compared with that of HPA group so magnesium sulphate with glycerin was more effective.

Similarly, there was no significant association between magnesium sulphate with glycerin dressing and heparinoid ointment application on management of phlebitis with selected socio-demographic variables and cannula related factors.

\section{Recommendations}

- Frequent monitoring of cannula site, early identification of cannula induced phlebitis and prompt intervention is essential for treatment and prevention of further complication.

- Nurses need to have adequate knowledge and skill regarding cannula induced phlebitis management and its complication prevention.

- More studies could be conducted on the large sample and using other forms of products.

\section{Conflicts of Interest}

The authors declare no conflicts of interest regarding the publication of this paper.

\section{References}

[1] McCallum, L. and Higgins, D. (2010) Care of Peripheral Venous Cannula Sites. Nursing Times, 108, 14-15. http://www.ncbi.nlm.nih.gov/pubmed/22953419

[2] Smeltzer, S. and Bare, B. (2013) Brunner and Suddarth's Textbook of Medical-Surgical Nursing. 10th Edition, Wolters Kluwer Pvt Ltd., New Delhi, India, 123.

[3] Denton, A. (2010) Standards for Infusion Therapy: Royal College of Nursing. 4th Edition, Royal College of Nursing, London.

http://www.rcn.org.uk/_data/assets/pdf_file/0005/78593/002179.pdf 
[4] Da Silva Almendra, P., et al. (2013) Incidence of Phlebitis in Patients Receiving Antibiotics Therapy through Peripheral Intravenous Catheters-A Safety ClusterRandomized Pilot Trial. Abstracts of the Critical Care Canada Forum, Toronto, Canada.

[5] Zheng, G.H., Yang, L., Chu, J.F. and Chen, H.Y. (2014) Aloe vera for Prevention and Treatment of Infusion Phlebitis. Database of Systematic Reviews, 6, CD009162. http://www.cochranelibrary.com

[6] WHO (2015) Health Care-Associated Infections Fact Sheet. World Health Organization, 4. http://www.who.int/gpsc/country_work/gpsc_ccisc_fact_sheet_en.pdf

[7] Singh, R., Bhandary, S. and Pun, K.D. (2008) Peripheral Intravenous Catheter Related Phlebitis and Its Contributing Factors among Adult Population at KU Teaching Hospital. Kathmandu University Medical Journal, 6, 443-447. https://doi.org/10.3126/kumj.v6i4.1732

[8] O'Grady, N.P., Alexander, M., Burns, L.A., Dellinger, E.P., Garland, J., Heard, S.O., et al. (2011) Summary of Recommendations: Guidelines for the Prevention of Intravascular Catheter-Related Infections. Clinical Infectious Diseases, 52, 1087-1099. https://doi.org/10.1093/cid/cir138

[9] Wasserman, R. (2015) Glycerin Ingredients | LIVESTRONG.COM. http://www.livestrong.com/article/201501-glycerin-ingredients

[10] Roth, E. (2013) The Effects of Glycerin on Skin | LIVESTRONG.COM. http://www.livestrong.com/article/78934-effects-glycerin-skin

[11] Soloman, V., Rajappa, T. and Malviya, S.D. (2015) Comparison of Heparinoid and Ichthammol Glycerine Application on Patients with Phlebitis. International Journal of Current Research, 7, 14615-14620.

[12] Hoff, D.S. and Jensen, P.D. (2001) Pediatric Pharmacotherapy. PSAP-IV, 4, 1-28.

[13] Yambem, M., Madhale, M. and Bagi, D. (2015) A Comparative Study to Assess the Effectiveness of Glycerin with Magnesium Sulphate Versus Heparin-Benzyl Nicotinate (Thrombophob) Ointment on Management of Thrombophlebitis among Patients Admitted in Intensive Care Units ( ICU ) of Selected Hospital. International Journal of Science and Research, 4, 2013-2016. http://www.ijsr.net

[14] Cicolini, G., Bonghi, A.P., Di Labio, L. and Di Mascio, R. (2009) Position of Peripheral Venous Cannulae and the Incidence of Thrombophlebitis: An Observational Study. Journal of Advanced Nursing, 65, 1268-1273. https://www.ncbi.nlm.nih.gov/pubmed/19374679 https://doi.org/10.1111/j.1365-2648.2009.04980.x

[15] Hedayatinejad, M., Fayazi, S., Jahani, S. and Sakimalehi, A. (2016) Survey of Complications of Peripheral Venous Catheterization at an Intensive Care Unit of (ICU) of Susa City. Jentashapir Journal of Health Research, 7, e33783.

[16] Tan, J.Y.W., Yeap, W.J. and Aznal, S.S.S. (2012) Risk Factors of Pheripheral Venous Catherization Thrombophlebitis. International e-Journal of Science, Medicine \& Education, 6, 24-30. http://www.nih.gov/pubmet/24583939

[17] Abdul-Hak, C.K. and Barros, Â.F. (2014) The Incidence of Phlebitis in a Medical Clinical Unit. Texto \& Contexto-Enfermagem, 23, 633-638. http://www.scielo.br/scielo.php?script=sci_arttext\&pid=S0104-07072014000300633 \&lng $=$ en \&nrm $=$ iso \&tlng $=$ en https://doi.org/10.1590/0104-07072014000900013

[18] Waitt, C., Waitt, P. and Pirmohamed, M. (2004) Intravenous Therapy. Postgraduate Medical Journal, 80, 1-6. http://www.ncbi.nlm.nih.gov/pubmed/14760169 https://doi.org/10.1136/pmj.2003.010421 
[19] Yoong, W., Tan, J., Yeap, J.W., Sulaiha, S. and Aznal, S. (2012) Risk Factors of Peripheral Venous Catheterization Thrombophlebitis. IeJSME, 6, 24-30. https://www.researchgate.net/publication/266203691

[20] Wallis, M.C.M., Mcgrail, M., Webster, J., Marsh, N., Gowardman, J. and Playford, G.E. (2014) Risk Factors for the Peripheral Intravenous Catheter Failure: A Multivariate Analysis of Data from a Randomized Controlled Trial. Infection Control \& Hospital Epidemiology, 35, 63-68. http://www.ncbi.nlm.nih.gov/pubmed/24334800 https://doi.org/10.1086/674398

[21] Marino, P. (2007) The ICU Book. 3rd Edition, Wolters Kluwer Pvt Ltd., India, New Delhi, 144.

[22] Oliveira, S.A. (2012) Incidence of Phlebitis in Patients with Peripheral Intravenous Catheters: The Influence of Some Risk Factors. Australian Journal of Advanced Nursing, 30, 32-39. https://www.ajan.com.au/archive/Vol30/Issue2/4Salgueiro-Oliveira.pdf

[23] Saini, R., Agnihotri, M. and Gupta, A.I. (2011) Epidemiology of Infiltration and Phlebitis. Nursing and Midwifery Research Journal, 7, 22-23.

http://medicine.nic.in/nad/t11/il/nadt 1il p22.pdf

[24] Perucca, R. and Micek, J. (1994) Treatment of Infusion-Related Phlebitis: Review and Nursing Protocol. J Intraven Nurs, 16, 282-286.

[25] Ravindra, H. and Patel, K.D. (2015) A Quasi Experimental Study to Evaluate Effectiveness of Glycerin Magnesium Sulphate Dressing on Phlebitis among Patients Undergoing Peripheral Intravenous Infusion in Selected Hospital, Vadodara. International Journal of Medical Research and Health Sciences, 4, 527-530.

http://www.indianjournals.com https://doi.org/10.5958/2319-5886.2015.00101.0

[26] Thomas, M. (2016) Prevalence of Phlebitis and Comparison of the Effectiveness of Topical Ichthammol Glycerin and Heparinoid Application on Phlebitis among Patients on Peripheral Intravenous Therapy. Journal of Medical Science and Clinical Research, 4, 12265-12271. http://www.jmscr.igmpublication.org https://doi.org/10.18535/jmscr/v4i8.96

[27] D’souza, B.L. and Shivakumar (2016) Effectiveness Magnesium Sulphate Crystal Fomentation vs Paste Application for Phlebitis among Children Receiving Peripheral Infusion Who Are Admitted at Selected Hospital at Mangalore. NUJHS, 6, 9-12. http://www.nitte.edu.in/journal/march2016/o6.pdf

[28] Yadav, C., Samuel, G., Bano, H., Mol, S., Jaiswal, P., Sootrakar, R., et al. (2016) Effectiveness of Alovera, Glycerin, and Cold Application on Superficial Thrombophlebitis among Patients. International Journal of Bioassays, 5, 4858-4861.

https://doi.org/10.21746/ijbio.2016.09.0013 